\title{
Echocardiographic screening discloses increased values of pulmonary artery systolic pressure in 9 of 68 unselected patients affected with hereditary hemorrhagic telangiectasia
}

Carla Olivieri, $P h D^{1, *}$, Lucav Lanzarini, $M D^{2, *}$, Fabio Pagella, $M D^{3}$, Lucia Semino, $M D^{3}$, Sabrina Corno, $M D^{3}$, Cristina Valacca, $P h D^{1}$, Henry Plauchu, $\mathrm{MD}^{4}$, Gaetan Lesca, $P h D^{5}$, Martine Barthelet, $M D^{6}$,

Elisabetta Buscarini, $\mathrm{MD}^{7}$, Cesare Danesino, $M D^{1,8}$

\begin{abstract}
Background: Hereditary hemorrhagic telangiectasia (HHT) is an autosomal dominant disorder characterized by the presence of telangiectases and arteriovenous malformations. In some families in whom a form of idiopathic pulmonary arterial hypertension cosegregated with HHT, mutations in the ACVRL1 gene were present. Purpose: We noninvasively measured the pulmonary artery systolic pressure (PASP) in a group of patients with HHT. Methods: Doppler transthoracic echocardiography and mutation analysis by direct sequencing were used. Results: We studied 68 patients (age 19-84 years, mean $50.75+15.11$; 32 females) and PASP measurement was possible in 44 (64. 7\%); in addition, 9 of them (20.5\%) showed elevated values. Molecular analysis identified mutations in the ACVRL1 gene in 7 of these 9 subjects. Even on exclusion of relatives of the single case with known pulmonary hypertension, 5 of 37 patients (13.5\%) still showed values higher than those of controls. Conclusion: The data indicate that elevated PASP values are a frequent and previously unrecognized complication of HHT. Because clinically significant pulmonary artery hypertension (a relevant cause of morbidity and mortality) may subsequently develop in these patients, we propose that the measurement of PASP should be included among the parameters recorded for all patients undergoing Doppler transthoracic echocardiography during routine clinical screening. Genet Med 2006:8(3):183-190.
\end{abstract}

Key Words: hereditary hemorrhagic telangiectasia, pulmonary artery systolic pressure, ACVRL1 gene, Doppler transthoracic echocardiography, ACVRL1 mutations

Hereditary hemorrhagic telangiectasia (HHT) (MIM $187300)$ is an autosomal dominant vascular dysplasia with the following characteristics: epistaxes and telangiectases are present in more than $95 \%$ of patients ${ }^{1,2}$; telangiectases involve the skin and mucosae (causing epistaxes and gastrointestinal bleeding that may be severe enough to require transfusions); visceral arteriovenous malformations (AVMs) are mainly observed in the liver ( $57 \%$ of patients), lungs (34\%), and brain

From the ${ }^{1}$ Biologia Generale e Genetica Medica, Università di Pavia, Pavia, Italy; ${ }^{2}$ Divisione di Cardiologia, IRCCS Policlinico "S. Matteo," Pavia, Italy; ${ }^{3}$ Clinica Otorinolaringoiatrica, Università di Pavia, IRCCS "S. Matteo," Pavia, Italy; ${ }^{4}$ Génétique Clinique, Hôpital Hotel Dieu and Università "C. Bernard," Lyon, France, coordinator of HHT French-Italian network; ${ }^{5}$ Laboratoire de Génétique, Hôpital Edouard Herriot and Università "C. Bernard," Lyon, France; ${ }^{6}$ Service d'exploration fonctionnelle cardiovasculaire, Hôpital Louis Pradel, Lyon, France; ${ }^{7}$ Unità Operativa di Gastroenterologia, Ospedale Maggiore, Crema, Italy; ${ }^{8}$ Genetica Medica, IRCCS Policlinico "S. Matteo," Pavia, Italy.

Cesare Danesino, MD, Genetica Medica, Via Forlanini 14, 27100 Pavia, Italy.

Submitted for publication September 19, 2005.

Accepted for publication January 2, 2006.

${ }^{*}$ C.O. (molecular investigations) and L.L. (clinical evaluation) equally contributed to this article.

DOI: 10.1097/01.gim.0000204463.77319.1c
$(9.7 \%)^{2}$ and may cause severe life-threatening complications. Neurologic complications (strokes, cerebral abscesses, seizures) may be prevented with appropriate treatment of pulmonary AVMs.

The diagnosis of HHT can be confirmed, according to $\mathrm{Cu}-$ raçao's criteria, ${ }^{3}$ when three of the four suggested diagnostic criteria (epistaxes, telangiectases, visceral lesions, first-degree affected relative) are present. The phenotype is highly variable, and penetrance is usually complete by the age of 40 years. ${ }^{1}$

Approximately $80 \%$ of patients with HHT carry mutations in either of two genes: Endoglin (ENG, OMIM 131195) (HHT1) or activin receptor-like kinase 1 (ACVRL1, OMIM 601284) (HHT2). ${ }^{4,5}$ Evidence for a third locus has also been reported. ${ }^{6,7}$ Association of the HHT phenotype with juvenile polyposis and mutations in the MADH4 gene have recently been demonstrated ${ }^{8}$ as well.

Pulmonary arterial hypertension $(\mathrm{PAH})$ is a progressive disorder in which an increased pulmonary vascular resistance is caused by occlusion of the smallest pulmonary arteries; subsequently, right ventricular failure may occur. ${ }^{9}$ A diagnosis of idiopathic pulmonary hypertension is proposed when $\mathrm{PAH}$ is observed in the absence of any known predisposing condition 
such as pulmonary embolism, connective tissue disease, and lung or heart disease. Women are affected twice as commonly as men. The familial form of "primary pulmonary hypertension" (OMIM 178600) is observed in approximately $10 \%$ of overall cases. ${ }^{10} \mathrm{It}$ is rare, with an incidence of approximately 1 in 100,000 to 1 in $1,000,000$, and inherited as an autosomal dominant trait with reduced penetrance; genetic anticipation was discussed by Deng et al. in 2000. ${ }^{11}$ Finally, mutations in the BMPR2 have also been identified. ${ }^{12}$

A form of PAH that is clinically and histologically indistinguishable from idiopathic pulmonary hypertension may occur in patients with HHT. In 2001, Trembath et al. ${ }^{13}$ demonstrated mutations in the ACVRL1 gene in patients who showed clinical features of both PAH and HHT; this observation was subsequently confirmed by other studies. ${ }^{14,15}$ All of these studies were carried out in patients (or families) with a known history of PAH in whom symptoms of HHT could also be identified; the mutations that have been identified are summarized in Table 1.

We studied a group of 68 subjects affected by HHT who did not display any clinical evidence of PAH to assess pulmonary artery systolic pressure (PASP) values. We were interested in the possible increase of PASP values, as well as in the frequency of the increase, and in correlating, if possible, elevated PASP with genotype.

Table 1

Previously reported ACVRL1-PH-related mutations

\begin{tabular}{|c|c|c|c|c|}
\hline Exon & Protein & Mut & Type & Reference \\
\hline 2 & $113 \mathrm{fs}(+1 \mathrm{aa})$ & $37 \operatorname{delC}^{b}$ & fs & 13 \\
\hline $5^{a}$ & D179A & $536 \mathrm{~A}>\mathrm{C}^{b}$ & mis & 14 \\
\hline 6 & G211D & $632 \mathrm{G}>\mathrm{A}^{b}$ & mis & 14 \\
\hline 6 & 254delD & $b$ & del & 13 \\
\hline 7 & $\mathrm{C} 344 \mathrm{Y}$ & $1031 \mathrm{G}>\mathrm{A}$ & mis & 14 \\
\hline 8 & R374W & $1120 \mathrm{C}>\mathrm{T}$ & mis & 14,15 \\
\hline 8 & R374Q & $1121 \mathrm{G}>\mathrm{A}$ & mis & 14 \\
\hline 8 & W399S & $1196 \mathrm{G}>\mathrm{C}^{b}$ & mis & 14 \\
\hline 8 & R411W & $1231 \mathrm{C}>\mathrm{T}^{b}$ & mis & 13 \\
\hline 8 & $\mathrm{R} 411 \mathrm{Q}$ & $1232 \mathrm{G}>\mathrm{A}$ & mis & 14 \\
\hline 10 & S462X & $1385 \mathrm{C}>\mathrm{G}^{b}$ & nons & 15 \\
\hline 10 & $\mathrm{R} 479 \mathrm{X}$ & $1435 \mathrm{C}>\mathrm{T}^{b}$ & nons & 15 \\
\hline 10 & R484WfsX493 & 1450C $>\mathrm{T}, 1450 \_1451$ insG $^{b}$ & fs & 15 \\
\hline 10 & R484W & $1450 \mathrm{C}>\mathrm{T}^{b}$ & mis & 13 \\
\hline 10 & K487T & $1460 \mathrm{~A}>\mathrm{C}^{b}$ & mis & 14 \\
\hline 10 & Q490X & $1468 \mathrm{C}>\mathrm{T}^{b}$ & nons & 13 \\
\hline
\end{tabular}

${ }^{a} A C V R L 1$ mutation found in a patient with PAH but no clinical signs of HHT.

${ }^{b}$ Mutations identified for the first time in patients with PAH and HHT.

\section{MATERIALS AND METHODS}

\section{Patients}

With Doppler transthoracic echocardiography (TTE), 68 consecutive patients (32 females) from 48 different families were screened, previously diagnosed with HHT by C.D., E.B., and F.P., according to Curaçao's criteria. ${ }^{3}$

None of the subjects studied had a personal clinical history suggesting PAH; cases 10 to 16 (Table 2) belong to a family with a known history of PAH in a single relative who was not included in the present study; the relatives tested were selected on the basis of HHT diagnostic criteria only.

In case 1 (Table 2), PAH was judged to be secondary to a mitral valve disease, whereas none of the other patients demonstrated any known risk factors (systemic disorders or exposure to chemicals). Six additional patients with HHT, known carriers of exon 10 mutations who were not included in the original group of 68, were studied in Lyon by B.M.

\section{Doppler transthoracic echocardiography}

Echocardiographic studies were performed on all patients using standard M-mode, two-dimensional, and Doppler echocardiographic evaluations. A commercially available GE-Vingmed ultrasound (System Five) (Horten, Norway) instrument and a 2.5 to 3.5 phased-array transducer were adopted for cardiac imaging, pulsed- and continuous-wave Doppler, and measurement of pulmonary pressure. A contrast echocardiographic study for verifying the presence of pulmonary AVMs was also performed in each patient. The Doppler method used for the evaluation of systolic pulmonary artery pressures is described in detail in a previous study. ${ }^{16}$ Measurements represent an average of three normal sinus rhythm beats. Pulsed- and continuous-wave Doppler echocardiographic velocity tracings were recorded on paper strip charts at a speed of $100 \mathrm{~mm} / \mathrm{sec}$.

Contrast echocardiography was performed in all patients according to Nanthakumar et al. ${ }^{17}$ After having excluded the presence of intracardiac shunt, 10 to $30 \mathrm{~mL}$ of agitated saline were injected into a peripheral vein. Appearance of a cloud of bubbles in the left atrium occurring at least three cardiac cycles after first appearance in the right atrium was considered confirmation of right-to-left pulmonary shunting because gas bubbles do not survive a normal capillary bed. The cardiologist performing the echocardiographic studies was blinded to the clinical history of patients and to the results of other diagnostic and laboratory tests.

Sex and age-related reference values for PASP, obtained by the same method, were reported by McQuillan et al. ${ }^{18}$

Catheter-derived pulmonary artery pressure estimates were then proposed to the patients who showed clear clinical indications and was subsequently performed in case 1 ; the procedure was refused by cases 2 and 4 .

\section{Molecular analysis}

DNA was obtained from peripheral blood after informed consent. Mutation analysis for ACVRL1 and ENG genes was 
Table 2

Italian patients: Clinical findings

\begin{tabular}{|c|c|c|c|c|c|c|c|}
\hline Case & ID & Sex/age & ePASP $(\mathrm{mm} \mathrm{Hg})$ & Case & ID & Sex/age & ePASP $(\mathrm{mm} \mathrm{Hg})$ \\
\hline 1 & HHT01:A101 & $f / 63$ & 58 & 36 & HHT23:101 & $\mathrm{m} / 67$ & 28 \\
\hline 2 & НHT02:A101 & $\mathrm{m} / 72$ & 50 & 37 & HHT23:201 & $\mathrm{m} / 40$ & $\mathrm{nv}$ \\
\hline 3 & HHT02:A201 & $\mathrm{f} / 42$ & 27 & 38 & HHT24:101 & $\mathrm{f} / 55$ & 27 \\
\hline 4 & ННT03:A101 & $f / 60$ & 50 & 39 & HHT25:101 & $\mathrm{m} / 53$ & 27 \\
\hline 5 & HНT03:A201 & $f / 33$ & 25 & 40 & HНT26:E203 & $f / 44$ & 25 \\
\hline 6 & HНT04:A101 & $\mathrm{m} / 71$ & 47 & 41 & HHT26:E201 & $\mathrm{m} / 52$ & $\mathrm{nv}$ \\
\hline 7 & HHT05:101 & $\mathrm{m} / 71$ & 43 & 42 & HHT27:A303 & $f / 52$ & 25 \\
\hline 8 & HНT06:101 & $f / 59$ & 42 & 43 & HHT27:A311 & $\mathrm{m} / 53$ & 25 \\
\hline 9 & НHT07:A101 & $f / 26$ & 40 & 44 & HHT28:101 & $\mathrm{m} / 48$ & 25 \\
\hline 10 & HНT08:A314 & $\mathrm{m} / 67$ & 40 & 45 & HHT29:A101 & $\mathrm{m} / 54$ & 25 \\
\hline 11 & HНT08:A406 & $\mathrm{f} / 55$ & 32 & 46 & HHT29:A201 & $\mathrm{m} / 28$ & $\mathrm{nv}$ \\
\hline 12 & HHT08:A506 & $f / 29$ & 30 & 47 & HНT30:101 & $\mathrm{m} / 60$ & 25 \\
\hline 13 & HHT08:A507 & $f / 25$ & 30 & 48 & HHT31:S201 & $\mathrm{m} / 19$ & 22 \\
\hline 14 & НHТ08:A418 & $f / 37$ & 23 & 49 & HHT31:S301 & $\mathrm{m} / 46$ & nv \\
\hline 15 & НHT08:A407 & $f / 52$ & 28 & 50 & HНT32:101 & $f / 28$ & 20 \\
\hline 16 & НHT08:А335 & $f / 56$ & $\mathrm{nv}$ & 51 & ННT33:101 & $f / 41$ & 20 \\
\hline 17 & HHT09:101 & $\mathrm{m} / 66$ & 40 & 52 & HНT34:E201 & $f / 29$ & $\mathrm{nv}$ \\
\hline 18 & HHT10:101 & $f / 59$ & 35 & 53 & HHT34:E203 & $\mathrm{m} / 26$ & $\mathrm{nv}$ \\
\hline 19 & HHT10:201 & $f / 56$ & $\mathrm{nv}$ & 54 & НHT35:101 & $f / 65$ & $\mathrm{nv}$ \\
\hline 20 & HHT11:A101 & $f / 65$ & 35 & 55 & HHT35:201 & $\mathrm{f} / 40$ & $\mathrm{nv}$ \\
\hline 21 & HHT11:A103 & $f / 56$ & 30 & 56 & HНT36:101 & $f / 50$ & $\mathrm{nv}$ \\
\hline 22 & HHT12:101 & $f / 84$ & 35 & 57 & HНT37:101 & $\mathrm{f} / 50$ & $\mathrm{nv}$ \\
\hline 23 & HHT13:101 & $\mathrm{m} / 73$ & 33 & 58 & HHT38:101 & $f / 59$ & $\mathrm{nv}$ \\
\hline 24 & HHT14:101 & $\mathrm{f} / 47$ & 32 & 59 & HHT39:101 & $\mathrm{f} / 76$ & $\mathrm{nv}$ \\
\hline 25 & HHT15:101 & $\mathrm{f} / 74$ & 32 & 60 & HHT40:101 & $\mathrm{m} / 28$ & $\mathrm{nv}$ \\
\hline 26 & HHT16:101 & $\mathrm{m} / 67$ & 32 & 61 & HHT41:101 & $\mathrm{m} / 30$ & $\mathrm{nv}$ \\
\hline 27 & HHT16:201 & $f / 38$ & 23 & 62 & HHT42:101 & $\mathrm{m} / 38$ & $\mathrm{nv}$ \\
\hline 28 & HHT17:101 & $\mathrm{m} / 25$ & 30 & 63 & HHT43:101 & $\mathrm{m} / 41$ & $\mathrm{nv}$ \\
\hline 29 & HHT18:101 & $\mathrm{m} / 47$ & 30 & 64 & HHT44:101 & $\mathrm{m} / 42$ & $\mathrm{nv}$ \\
\hline 30 & HHT19:101 & $\mathrm{m} / 56$ & 30 & 65 & HHT45:E101 & $\mathrm{m} / 51$ & $\mathrm{nv}$ \\
\hline 31 & HHT20:101 & $\mathrm{m} / 64$ & 30 & 66 & HHT46:101 & $\mathrm{m} / 52$ & $\mathrm{nv}$ \\
\hline 32 & HHT21:101 & $\mathrm{m} / 65$ & 30 & 67 & HHT47:101 & $\mathrm{m} / 70$ & $\mathrm{nv}$ \\
\hline 33 & HHT22:101 & $\mathrm{m} / 44$ & 29 & 68 & HHT48:101 & $\mathrm{m} / 72$ & $\mathrm{nv}$ \\
\hline 34 & HHT22:103 & $\mathrm{m} / 47$ & 25 & & & & \\
\hline 35 & HHT22:105 & $\mathrm{m} / 41$ & $\mathrm{nv}$ & & & & \\
\hline
\end{tabular}

Cases belonging to the same families have the same family number in the ID. In bold, patients with ePASP values out of the 95\% confidence interval (CI). ePASP, estimated pulmonary artery systolic pressure.

performed according to Olivieri et al. ${ }^{19}$; primers for exon amplification were obtained through the Genome Data Base ${ }^{20}$ or designed by O.C. using Primer 3 Input Software. ${ }^{21}$ Molecular analysis of the French patients was performed by L.G. as described in Lesca et al. ${ }^{22}$

\section{RESULTS}

A synopsis of TTE measurement of PASP and the patients' molecular results is included in Tables 2 and 3; the results from the French group are shown in Table 4. 
Table 3

Italian patients: Molecular findings

\begin{tabular}{|c|c|c|c|c|c|}
\hline \multirow[b]{2}{*}{ Case } & \multicolumn{4}{|c|}{ Mutation } & \multirow[b]{2}{*}{ References } \\
\hline & Gene & Exon & Genome & Protein & \\
\hline 29 & $A C V R L 1$ & E3 & c. G152A & C51Y & 34 \\
\hline 68 & $A C V R L 1$ & E3 & c. $\Delta \mathrm{T}_{164} \mathrm{GGTGC}_{169}$ & $\Delta \mathrm{L} 55 \mathrm{~V} 56$ in frame & Unpublished \\
\hline 42,43 & ACVRL1 & E3 & c. G172T & E58X & 19 \\
\hline 23 & $A C V R L 1$ & E3 & c. 203 ins G & G68 fs X166 & Unpublished \\
\hline 24 & ACVRL1 & E3 & c. G235A & G79R & Unpublished \\
\hline $20,21,45,46$ & ACVRL1 & E3 & c. $\Delta \mathrm{C}_{289} \mathrm{ACAAC}_{294}$ & $\Delta \mathrm{H} 97 \mathrm{~N} 98$ in frame & 19 \\
\hline 17 & ACVRL1 & $\mathrm{E} 4$ & c. $321 \mathrm{del} \mathrm{A}$ & Q107 fs X121 & Unpublished \\
\hline 59 & ACVRL1 & $\mathrm{E} 4$ & c. $\mathrm{C} 430 \mathrm{~T}$ & $\mathrm{R} 144 \mathrm{X}$ & 35 \\
\hline 67 & $A C V R L 1$ & E7 & c. $824 \mathrm{duplGGCT}$ & L273 fs X392 & Unpublished \\
\hline 9 & $A C V R L 1$ & E8 & c. T1127A & M376K & Unpublished \\
\hline 1 & ACVRL1 & E8 & c. T1139G & V380G & 36 \\
\hline 6 & ACVRL1 & E8 & c. C1199A & $\mathrm{A} 400 \mathrm{D}$ & 19 \\
\hline 2,3 & $A C V R L 1$ & E8 & c. G1232A & R411Q & 37 \\
\hline $10-16$ & $A C V R L 1$ & E10 & c. $\mathrm{C} 1435 \mathrm{~T}$ & $\mathrm{R} 479 \mathrm{X}$ & 22 \\
\hline 4,5 & ACVRL1 & E10 & c. $\mathrm{C} 1450 \mathrm{~T}$ & $\mathrm{R} 484 \mathrm{~W}$ & 13 \\
\hline 65 & $E N G$ & E3 & c. $\mathrm{C} 277 \mathrm{~T}$ & R93X & 38 \\
\hline 58 & $E N G$ & E6 & c. $\mathrm{C}_{780}$ Ins (Dupl $\mathrm{C}_{768}-\mathrm{G}_{775}$ ) & S260 fs X358 & Unpublished \\
\hline 52,53 & $E N G$ & E6 & g. IVS $6+5 \mathrm{~g}->\mathrm{c}$ & Splicing & Unpublished \\
\hline 26,27 & $E N G$ & E11 & c. $\Delta \mathrm{G} 1478$ & S492 fs X516 & Unpublished \\
\hline 40,41 & $E N G$ & Linkage & & & \\
\hline
\end{tabular}

The TTE method permitted PASP measurement in 44 of 68 patients $(64.7 \%)$ whose mean age was $50.75 \pm 15.11$ years (range 19-84 years); 23 were females.

The absence of tricuspid valve regurgitation prevented PASP measurement in 24 patients; this finding, associated with normal right ventricular morphology and normal 12-lead electrocardiogram (ECG), suggests normal right ventricular function, rendering PAH extremely unlikely in this subset of patients.

Table 4

French patients: Clinical and molecular findings

\begin{tabular}{|c|c|c|c|c|c|c|c|}
\hline \multirow[b]{2}{*}{ ID } & \multirow[b]{2}{*}{ Sex } & \multirow[b]{2}{*}{ Age } & \multicolumn{4}{|c|}{ Mutation } & \multirow[b]{2}{*}{ ePASP } \\
\hline & & & Gene & Exon & Type & Protein & \\
\hline 764 & $\mathrm{~F}$ & 51 & $A C V R L 1$ & E10 & Nons & $\mathrm{R} 479 \mathrm{X}$ & Normal \\
\hline 27769 & F & 70 & $A C V R L 1$ & E10 & Misse & R479Q & Normal \\
\hline 23974 & $\mathrm{M}$ & 63 & $A C V R L 1$ & E10 & Nons & R479X & Normal \\
\hline 25398 & $\mathrm{M}$ & 74 & $A C V R L 1$ & E10 & Nonsense & $\mathrm{R} 479 \mathrm{X}$ & Normal \\
\hline 26600 & $\mathrm{~F}$ & 53 & $A C V R L 1$ & E10 & Duplication & Dupl R484 & Normal \\
\hline 22480 & $\mathrm{~F}$ & 59 & $A C V R L 1$ & E10 & Missense & $\mathrm{R} 479 \mathrm{~L}$ & $25 \mathrm{~mm} \mathrm{H}$ \\
\hline 26480 & $\mathrm{~F}$ & 57 & $A C V R L 1$ & E10 & Missense & $\mathrm{R} 484 \mathrm{Q}$ & $35 \mathrm{~mm} \mathrm{H}$ \\
\hline
\end{tabular}

ePASP, estimated pulmonary artery systolic pressure.
The PASP values observed in our group of patients with HHT (44 cases, mean: $30.83 \pm 7.87 \mathrm{~mm} \mathrm{Hg}$ ) were compared with the reference values for the different age groups from the large study by McQuillan et al. ${ }^{18}$ (3790 controls: mean $28.3 \pm$ $4.9 \mathrm{~mm} \mathrm{Hg}$ ) and entered in Figure 1A (males) and B (females). No statistical tests were applied to the two groups because of the large difference in their size.

Nine unrelated patients with HHT (four females) showed PASP values higher than 1 standard deviation (SD) for their age group, and six of them (four females) had PASP values outside the $95 \%$ confidence interval $(\mathrm{CI})$; seven of nine subjects (cases 1, 4, 7, $8,9,10$, and 17) with elevated PASP values showed contrast echocardiographic evidence of right-to-left pulmonary shunting.

In case 1, a previously undiagnosed significant mitral stenosis plus regurgitation was first identified by echocardiography performed for the purposes of the present study; the increased value of PASP in this case was judged to be mostly secondary to the valvular abnormality, and this case was not considered in the analysis of results or in the discussion.

The involvement of BMPR2 was excluded in the only family whose size made it suitable for haplotype analysis (cases 10-16, data not shown).

After the identification of mutations in exon 10 of ACVRL1 (Table 3) in two of nine subjects with increased PASP values, 
A Males
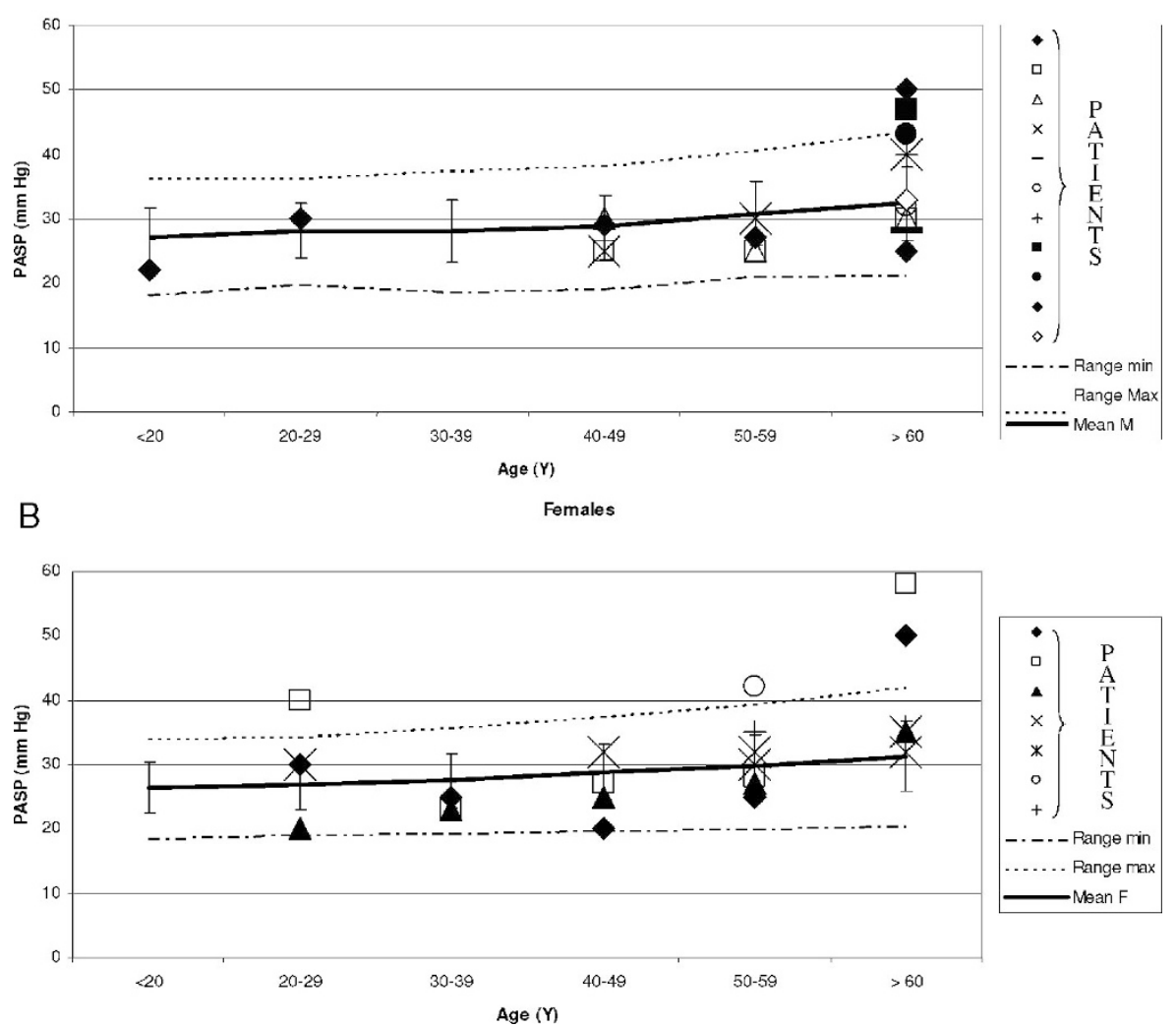

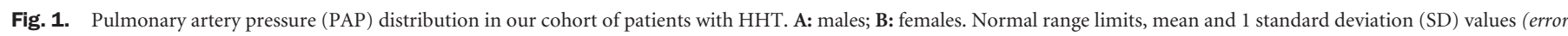
bars) as in McQuillan et al. ${ }^{18}$

mutations that have already been reported in patients with HHT and PAH (Table 1), ${ }^{13-15}$ we tested PASP in six other patients with HHT carrying ACVRL1 exon 10 mutations, all of whom showed normal findings (Table 4) (MB in Lyon).

Mutations found in either ENG or ACVRL1 are listed in Table 3; in 27 subjects, a mutation in ACVRL1 was found, whereas eight subjects (three of eight showing normal PASP values and five of eight with no tricuspid regurgitation, and thus nonmeasurable PASP) carried an ENG mutation.

Cases 10 to 16, in whom the R479X mutation in ACVRL1 was found, are relatives of a patient (not included in the present report) who was diagnosed with $\mathrm{PAH}$ and who underwent lung transplantation at age 20 years; the diagnosis of HHT was made only several years later. She belongs to a very large family ( $>50$ people in the pedigree), and no diagnosis of PAH was proposed for any of her other relatives. Cases 12 and 13 (Table 2) are at the upper limit for PASP for their age group, and case 10 is above $1 \mathrm{SD}$; other relatives are fully within normal limits (cases 11, 14, and 15) or not measurable (case 16); these data are in keeping with the reduced penetrance of PAH due to the ACVRL1 mutation.

The mother of the index case in this family (case 16) at age 56 years showed no tricuspid regurgitation and normal ECG; similarly, case 15 (the mother of cases 12 and 13) at age 52 years was fully normal, whereas her daughters have PASP at +1 SD compared with normal controls.
In our group of patients with HHT, we collected data from seven additional parent/child pairs: in five of them both parent and child were completely within normal limits or not measurable (cases 26 and 27; 36 and 37; 45 and 46; 48 and 49; 54 and 55; Table 2), whereas in two families (father/daughter and mother/daughter, cases 2 and 3, and 4 and 5, Table 2), the parent presented with a PASP value above the upper range limit, whereas their offspring showed PASP values within normal limits.

\section{DISCUSSION}

The association of PAH with HHT in the same family or the same subject was first reported by Trembath et al. ${ }^{13}$ and subsequently confirmed by several authors ${ }^{14,15,23}$ in 23 cases. All of the families in whom both $\mathrm{PAH}$ and HHT were present carried mutations in the ACVRL1 gene, and mutations or linkage to $B M P R 2$ was consistently excluded. The 16 different mutations were scattered over several exons, but 11 of 16 were localized in exon 8 or 10 (Table 1).

Three patients who carried an ENG mutation and showed PAH were reported as having a known intake of dexfenfluramine, a drug that is known to possibly cause $\mathrm{PAH}$, or as having other well-known causes for increased pulmonary artery pressure $^{14,24}$; a further case carrying a branch site mutation of ENG was recently reported by Harrison et al..$^{25}$ 
All cases or families reported up to now have been selected on the basis of a clinical diagnosis of PAH associated with symptoms of HHT.

In the course of a general clinical screening program on patients diagnosed with HHT according to Curaçao's criteria, ${ }^{3}$ but who evidenced no clinical evidence of $\mathrm{PAH}$, we obtained PASP data by using TTE in 44 of 68 patients.

This method is suitable for obtaining reliable estimates of PASP because the measurements obtained strictly correlate with those acquired by means of invasive procedures (concordance correlation coefficient $0.88,95 \%$ CI $0.82-0.93) .{ }^{16}$ Indeed, TTE has been considered a routine method for noninvasive PASP assessment by several other groups ${ }^{26,27}$; in addition, it makes it possible to obtain more general information on heart anatomy and function, including the right-sided chambers.

TTE proved useful in case 1 , in whom a previously undiagnosed mitral valve disease was present; naturally, when the patient's cardiologic evaluation showed abnormalities that required further diagnostic steps, invasive procedures were also performed with consistent results (case 1, PASP $41 \mathrm{~mm} \mathrm{Hg}$ by right-sided heart catheterization), as expected.

Overall, 8 of 44 patients (excluding case 1) (18.2\%, three females) showed PASP values above $1 \mathrm{SD}$, and five of them were also above the upper 95\% CI for age-related controls (Fig. $1 \mathrm{~A}$ and $\mathrm{B})$.

Our results indicate that PASP values exceeding control values may be found in a relevant proportion (5/44, 3 females, $11.4 \%$ ) of patients selected solely on the basis of a diagnosis of HHT, without overt signs of PAH. Moreover, in the large reference study by McQuillan et al., ${ }^{18} 28 \%$ of healthy subjects, irrespective of age or other parameters, had PASP values greater than $30 \mathrm{~mm} \mathrm{Hg}$, whereas in our group this figure increases to $34.1 \%$ (15/44); indeed, if cases of PASP values 30 $\mathrm{mm} \mathrm{Hg}$ or greater are considered, this statistic increases to $54.5 \%(24 / 44)$.

Among patients with increased PASP values, five of nine also showed hepatic arteriovenous fistulae. These were of limited size and number (grade 1 or 2 according to Buscarini et al..$^{28}$ ) and did not cause a significant increase of right atrial flow as assessed both by normal appearance of the right atrial component of $\mathrm{P}$ wave on standard ECG and by absence of right atrial dilatation on TTE. Therefore, these fistulae do not seem to be related to the observed changes in PASP.

No data are currently available on the course of PASP levels in patients with HHT to assess whether these high values will increase over time to develop into a fully expressed PAH or not; on the basis of our results, we now recommend a yearly follow-up with TTE to all patients with PASP values at or above $1 \mathrm{SD}$ over the mean; this is in agreement with the protocol suggested by Daniels et al. ${ }^{27}$ for serendipitously diagnosed cases of mild asymptomatic pulmonary hypertension.

Estimated PASP values and mutation analysis in the family to which cases 10 to 16 belong (see "Results") are in keeping with the reduced penetrance of PAH due to ACVRL1 mutation and with previous observations of some families in whom the appearance of PAH may show age anticipation between generations. ${ }^{29}$

On the basis of familial recurrence of PAH in families with HHT, we believe that patients with HHT such as cases 3 and 5 (with normal PASP values but one parent with increased values), should be offered the same follow-up as for subjects with confirmed increase of PASP values.

We also selected six additional patients solely on the basis of presence of mutations in exon 10 from the cohort of HHT cases reported by Lesca et al. ${ }^{22}$ because this exon has frequently been reported (Table 1) to bear PAH-related mutations; however, in these additional cases TTE failed to demonstrate increased values of PASP (Table 4).

Overall, we found more mutations in the ACVRL1 gene than in $E N G$ (Table 3); this irregular distribution is in keeping with similar data provided by Lesca et al. ${ }^{22}$ in the French population, and with our unpublished data on more than 100 index cases from among the Italian population.

The distribution of mutations of the ACVRL1 gene in HHT/ $\mathrm{PAH}$ is peculiar in the sense that 11 of 16 reported mutations $(68.8 \%)$ are localized in exons 8 and 10; these two exons contain only $30 \%$ to $35 \%$ of the variously reported mutations when taking into consideration the reviews by Abdalla and Letarte, ${ }^{30}$ and van den Driesche et al. ${ }^{31}$ the data by Lesca et al., ${ }^{22}$ and our unpublished results.

Among the mutations we found in patients with HHT with increased PASP (Table 3), two of six are in exon 10 and have already been described in patients with PAH and HHT; the others are in exon 8 , and one of them was previously unreported.

Mutations occurring in exon 8 frequently cause the modification of an arginine residue; R437 and R411 have so far been involved five times and are thus likely to be mutation hot spots. The possible mechanism to explain the frequent involvement of arginine residues has been discussed by Abdalla et al. ${ }^{32}$

Exon 10 contains the NANDOR BOX, relevant for the regulation of TGFbeta signaling, ${ }^{15,33}$ and four of six mutations fell into this region, as did the two mutations we observed where codon 479 was more frequently involved.

The only known mutation of exon 5 of ACVRL1 was observed in a patient with PAH who did not, however, show any clinical signs or have a family history of HHT. ${ }^{14}$

At present, $\mathrm{PAH}$ was observed only in association with HHT2; this observation, if confirmed, would be a defined genotype-phenotype correlation for ACVRL1 mutations.

It is clearly essential to document more cases to verify whether mutations in exons 8 and 10 in general, or those previously discussed in particular, possibly constitute a specific genetic risk factor for developing PAH.

In our group of patients with HHT, if we exclude all the cases from the family with a single known patient affected with $\mathrm{PAH}$ together with case 1, we still have 5 of 37 (13.5\%) cases with PASP values of the normal range; this suggests that this seemingly abnormal finding may in fact be much more common than previously thought. Thus our data add confirmatory evidence to recent reports by Harrison et al. ${ }^{14}$ and Abdalla et al..${ }^{15}$ demonstrating that 
PAH should be considered a possible severe complication in the course of HHT.

Presently, TTE is being used in the routine clinical workup of patients affected by HHT to assess the presence of lung AVMs. We believe that PASP measurement should also be attempted in all HHT cases, and certainly in those patients carrying mutations previously demonstrated to be associated with PAH.

TTE is a noninvasive test, well tolerated by patients, that can even be safely performed in children, a relevant point in view of the increasing number of cases of PAH observed in pediatric age, ${ }^{25,13,29}$ and in light of the possible anticipation of symptoms.

In conclusion, the pathway by which ENG and ACVRL1 regulate transforming growth factor-beta signaling includes a large number of genes and proteins; it is therefore highly likely that other unreported associations between HHT and apparently unrelated diseases may be discovered in the future by means of a more careful and focused clinical examination of large series of patients.

\section{ACKNOWLEDGMENTS}

This work was partially supported by grant $n^{\circ} 80170$, IRCCS Policlinico "S. Matteo" of Pavia, "Fondazione Cariplo," Milano, and "Fondazione Banca del Monte di Lombardia," Pavia, Italy. We thank the "Fondazione Italiana "O. Carini" per la Teleangectasia Emorragica Ereditaria" for their constant support, the physicians reporting single cases, in particular Dr. Cyril Goizet, Dr. Laurence Faivre, and Dr. Ghislaine Plessis, and all of the patients and their families.

\section{References}

1. Porteous MEM, Burn J, Proctor SJ. Hereditary haemorrhagic telangiectasia: a clinical analysis. J Med Genet 1992;29:527-530.

2. Lesca G, Olivieri C, Burnichon N, Boutitie F, et al. Genotype/phenotype correlation in hereditary hemorrhagic telangiectasia type 1 and 2 in France and Northern Italy. Paper presented at VI HHT-ROW Scientific Conference, Lyon (France), April 22$24,2005$.

3. Shovlin CL, Guttmacher AE, Buscarini E, FaughnanME, et al. Diagnostic criteria for hereditary hemorrhagic telangiectasia (Rendu-Osler-Weber syndrome). Am J Med Genet 2000;91:66-67.

4. Lesca G, Burnichon N, Plauchu H, Raux G, et al. Extensive molecular screening of ENG and ALK1 mutations in hereditary hemorrhagic telangiectasia French patients. Paper presented at VI HHT-ROW Scientific Conference, Lyon (France), April 22$24,2005$.

5. Prigoda N, Zhang K, andezande K, Savas S, et al. Highly sensitive, efficient and rapid identification of mutations in ENG and ALK-1 improves care for hereditary hemorrhagic telangiectasia families. Paper presented at VI HHT-ROW Scientific Conference, Lyon (France), April 22-24, 2005.

6. Wallace GM, Shovlin CL. A hereditary haemorrhagic telangiectasia family with pulmonary involvement is unlinked to the known HHT genes, endoglin and ALK-1. Thorax 2000;55:685-690.

7. Cole SG, Begbie ME, Wallace GM, Shovlin CL. A new locus for hereditary haemorrhagic telangiectasia (HHT3) maps to chromosome 5. J Med Genet 2005;42:577582.

8. Gallione CJ, Repetto GM, Legius E, Rustgi AK, et al. A combined syndrome of juvenile polyposis and hereditary haemorrhagic telangiectasia associated with mutations in MADH4 (SMAD4). Lancet 2004;363:852-859.

9. Gaine SP, Rubin LJ, et al. Primary pulmonary hypertension. Lancet 1998;352:719725.

10. Loyd JE, Primm RK, Newman JH, et al. Familial primary pulmonary hypertension: clinical patterns. Am Rev Respir Dis 1984;129:194-197.
11. Deng Z, Morse JH, Slager SL, Cuervo N, et al. Familial primary pulmonary hypertension (gene PPH1) is caused by mutations in the bone morphogenetic protein receptor-II gene. Am J Hum Genet 2000;67:737-744.

12. International PPH Consortium, Lane KB, Machado RD, Pauciulo MW, et al. Heterozygous germline mutations in BMPR2, encoding a TGF-beta receptor, cause familial primary pulmonary hypertension. Nat Genet 2000;26:81-84.

13. Trembath RC, Thomson JR, Machado RD, Morgan NV, et al. Clinical and molecular genetic features of pulmonary hypertension in patients with hereditary hemorrhagic telangiectasia. N Engl J Med 2001;345:325-334.

14. Harrison RE, Flanagan JA, Sankelo M, Abdalla SA, et al. Molecular and functional analysis identifies ALK-1 as the predominant cause of pulmonary hypertension related to hereditary haemorrhagic telangiectasia. J Med Genet 2003;40:865-871.

15. Abdalla SA, Gallione CJ, Barst RJ, Horn EM, et al. Primary pulmonary hypertension in families with hereditary haemorrhagic telangiectasia. Eur Respir J 2004;23:373-377.

16. Lanzarini L, Fontana A, Lucca E, Campana C, et al. Noninvasive estimation of both systolic and diastolic pulmonary artery pressure from Doppler analysis of tricuspid regurgitant velocity spectrum in patients with chronic heart failure. Am Heart J 2002;144:1087-1094.

17. Nanthakumar K, Graham AT, Robinson TI, Grande RN, et al. Contrast echo for detection of pulmonary arteriovenous malformations. Am Heart J 2001;141:243-246.

18. McQuillan BM, Picard MH, Leavitt M, Weyman AE. Clinical correlates and reference intervals for pulmonary artery systolic pressure among echocardiographically normal subjects. Circulation 2001;104:2797-2802.

19. Olivieri $\mathrm{C}$, Mira E, Delù $\mathrm{G}$, Pagella $\mathrm{F}$, et al. Identification of 13 new mutations in the $A C V R L 1$ gene in a group of 52 unselected Italian patients affected by hereditary hemorrhagic telangiectasia. J Med Genet 2002;39:E39.

20. GDB(TM) Human Genome Database [database online]. The Official WorldWide Database for the Annotation of the Human Genome Hosted by RTI International, North Carolina. Available at: http://www.gdb.org/. Accessed February 6, 2006.

21. Primer 3 Input (primer3_www.cgi v 0.2): Steve Rozen and Helen J Skaletsky (2000) Primer 3 on the WWW for general users and for biologist programmers. In: Bioinformatics Methods and Protocols: Methods in Molecular Biology. Krawetz S Misener S (Eds). Totowa, NJ: Humana Press, 2000:365-386. Available at:http://frodo.wi.mit. edu/cgi-bin/primer3/primer3_www.cgi. Accessed February 6, 2006.

22. Lesca G, Plauchu H, Coulet F, Lefebvre S, et al. Molecular screening of ALK1/ $A C V R L 1$ and ENG genes in hereditary hemorrhagic telangiectasia in France. Hum Mutat 2004;23:289-299.

23. Olivieri C, Malvezzi L, Lanzarini L, Pagella F, et al. PPH and HHT: the first Italian family studied shows a mutation in the ACVRL1 gene. Paper presented at 5th HHT Scientific Conference, Bonaire (the Netherland Antilles), April 24-28, 2003.

24. Chaouat A, Coulet F, Simonneau G, Weitzenbaum E, et al. Endogline germline mutation, hereditary hemorrhagic telangiectasia and dexfenfluramine-associated pulmonary arterial hypertension. Am J Respir Crit Care Med 2003;167:A842.

25. Harrison RE, Berger R, Haworth SG, Tulloh R, et al. Transforming growth factorbeta receptor mutations and pulmonary arterial hypertension in childhood. Circulation 2005;111:435-441.

26. Kim NH. Diagnosis and evaluation of the patient with pulmonary hypertension. Cardiol Clin 2004;22:367-373.

27. Daniels LB, Krummen DE, Blanchard DG. Echocardiography in pulmonary vascular disease. Cardiol Clin 2004;22:383-399.

28. Buscarini E, Danesino C, Plauchu H, de Fazio C, et al. High prevalence of hepatic focal nodular hyperplasia in subjects with hereditary hemorrhagic telangiectasia. Ultrasound Med Biol 2004;30:1089-1097.

29. Deng Z, Morse JH, Slager SL, Cuervo N, et al. Familial primary pulmonary hypertension (gene PPH1) is caused by mutations in the bone morphogenetic protein receptor-II gene. Am J Hum Genet 2000; 67:737-744.

30. Abdalla SA, Letarte M. Hereditary haemorrhagic telangiectasia: current views on genetics and mechanisms of disease. JMed Genet 2005; May 6: [Epub ahead of print.]

31. van den Driesche S, Mummery CL, Westermann CJ. Hereditary hemorrhagic telangiectasia: an update on transforming growth factor beta signaling in vasculogenesis and angiogenesis. Cardiovasc Res 2003;58:20-31.

32. Abdalla SA, Cymerman U, Johnson RM, Deber CM, et al. Disease-associated mutations in the conserved residues of the ALK-1 kinase domain. Eur J Hum Genet 2003;11:279-287.

33. Garamszegi N, Dore JJ, Penheiter SG, Edens M, et al. Transforming growth factor beta receptor signaling and endocytosis are linked through a $\mathrm{COOH}$ terminal activation motif in the type I receptor. Mol Biol Cell 2001;12:2881-2893.

34. Klaus DJ, Gallione CJ, Anthony K, Yeh EY, et al. Novel missense and frameshift mutations in the activin receptor-like kinase-1 gene in hereditary hemorrhagic telangiectasia. Hum Mutat 1998;12:137. 


\section{Olivieri et al.}

35. Paquet ME, Pece-Barbara N, Vera S, Cymerman U, et al. Analysis of several endoglin mutants reveals no endogenous mature or secreted protein capable of interfering with normal endoglin function. Hum Mol Genet 2001;10:1347-1357.

36. Letteboer TG, Zewald RA, Kamping EJ, de Haas G, et al. Hereditary hemorrhagic telangiectasia: ENG and ALK-1 mutations in Dutch patients. Hum Genet 2005;116: 8-16.
37. Johnson DW, Berg JN, Baldwin MA, Gallione CJ, et al. Mutations in the activin receptor-like kinase 1 gene in hereditary haemorrhagic telangiectasia type 2. Nat Genet 1996;13:189-195.

38. Cymerman U, Vera S, Pece-Barbara N, Bourdeau A, et al. Identification of hereditary hemorrhagic telangiectasia type 1 in newborns by protein expression and mutation analysis of endoglin. Pediatr Res 2000;47:24-35. 